\title{
SALVAGE OF RIGHT GASTROEPIPLOIC ARTERY GRAFT BEFORE PANCREATODUODENECTOMY
}

Toshiya Ohtsuka, MD, ${ }^{\text {a }}$ Yoshihiro Suematsu, MD, ${ }^{\text {a }}$ Hiroshi Kubota, MD, ${ }^{\text {a }}$ Shinichi Takamoto, MD, ${ }^{\text {a }}$ and Masatoshi Makuuchi, MD, PhD, ${ }^{\text {b }}$ Tokyo, Japan

A patent right gastroepiploic artery (GEA) graft in situ to the coronary artery can create disturbance when upper abdominal operations are carried out. This communication describes a surgical technique for rescue of a functioning GEA graft before pancreatoduodenectomy; saphenous vein grafting from the right axillary artery to the GEA graft through an intrapleural route.

Patient and operation. The patient was a 62-year-old woman who had icterus and anorexia. A diagnosis of bile duct cancer was made, and pancreatoduodenectomy was planned. Five years before, she had undergone a coronary artery bypass operation through a full sternotomy, including the internal thoracic artery and GEA conduits in situ to the left anterior descending and posterior descending coronary arteries and a vein graft from the ascending aorta to the posterolateral branch of the circumflex artery. Preoperative angiography and contrast-enhanced computed tomography demonstrated that the GEA graft from the gastroduodenal artery passed through the antegastric, antehepatic, and transdiaphragmatic route, and its flow extensively covered the inferior wall of the left ventricle. Therefore, before the standard pancreatoduodenectomy, an operation was carried out to salvage the functioning GEA.

Electrocardiography, the left radial arterial line, the SwanGanz catheter (Baxter Healthcare Corporation, Edwards Division, Santa Ana, Calif), and transesophageal echocardiography were used for monitoring. A saphenous vein graft was harvested from the right leg, and a $3-\mathrm{cm}$ right infraclavicular incision was made to expose the right axillary artery. An 8-cm median longitudinal incision was made for a partial resternotomy and minilaparotomy. The limited sternotomy was reverse L-shaped, with its transverse cut at the level of the fourth intercostal space. The right ventricle and atrium were carefully dissected from the sternum just as far as the right pleural cavity. Through the minilaparotomy, the GEA pedicle on the liver tissue was identified. Eight thousand units of heparin was given, maintaining an activated clotting time of 280 seconds, and an end-to-side anastomosis was created between the vein graft and the axillary artery. Under thoracoscopic guidance, the vein graft was delivered into the right

From the Department of Cardiothoracic Surgery a and Division of Hepato-Biliary-Pancreatic Surgery, ${ }^{\mathrm{b}}$ Faculty of Medicine, University of Tokyo, Tokyo, Japan.

J Thorac Cardiovasc Surg 2001;121:1013-4

Copyright $\odot 2001$ by The American Association for Thoracic Surgery

0022-5223/2001 $\$ 35.00+0 \quad \mathbf{1 2 / 5 4 / 1 1 0 6 7 5}$

doi: $10.1067 / \mathrm{mtc} .2001 .110675$

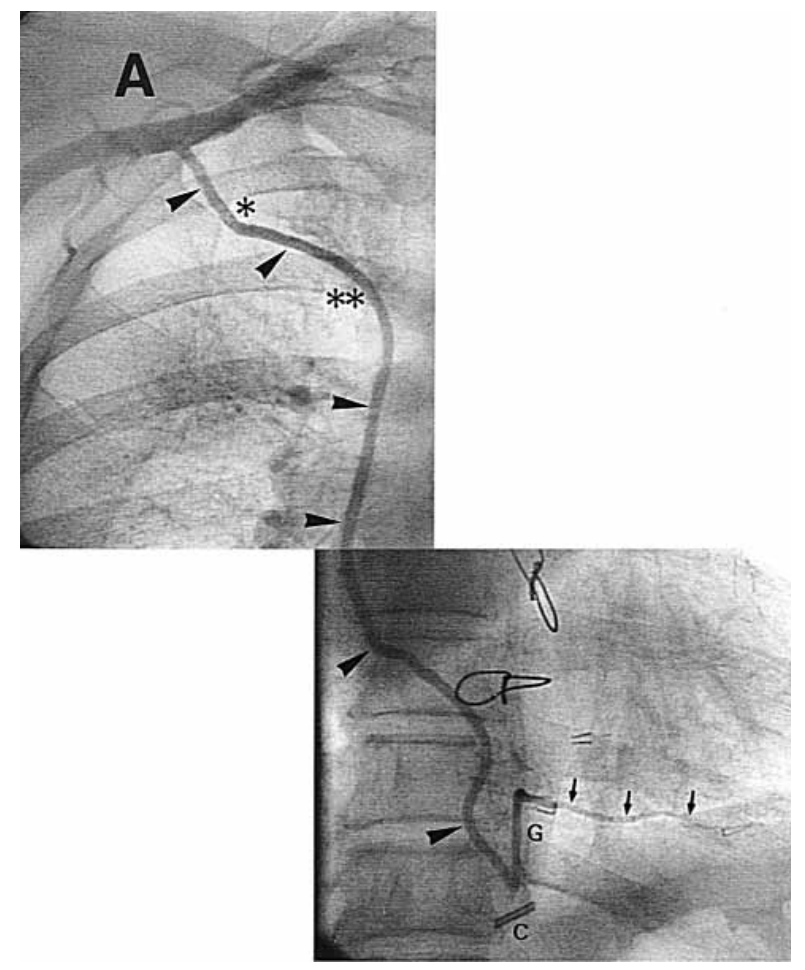

Fig 1. Postoperative angiogram of vein graft (arrowheads) from the axillary artery $(A)$ to the $\operatorname{GEA}(G)$, with perfusion to the posterior descending coronary artery (arrows). Doublecurve formation along the vein graft is seen where the graft enters the right pleural cavity through the first intercostal space $(*)$ and contacts the medial margin of the right lung (**). $C$, Clips ligating GEA.

pleural space through a tunnel created at the first intercostal space, laid on the mediastinum, brought out from the right intrathoracic space near the diaphragm, and advanced to the GEA graft on the liver tissue. Ischemic preconditioning for the GEA, involving 5-minute occlusion and release, was carried out, and the vein graft was anastomosed to the GEA in an end-to-side manner. The GEA was then ligated with clips just proximal to the anastomosis. During the ischemic preconditioning and the occlusion period for anastomosis (18 minutes), neither ischemic change nor hemodynamic deterioration was observed on the monitors.

Postoperative course was uneventful, and angiography carried out 3 days after the operation confirmed the patency of the vein graft (Fig 1). Ten days after the operation, pancreatoduodenectomy was carried out; the gastroduodenal artery was 


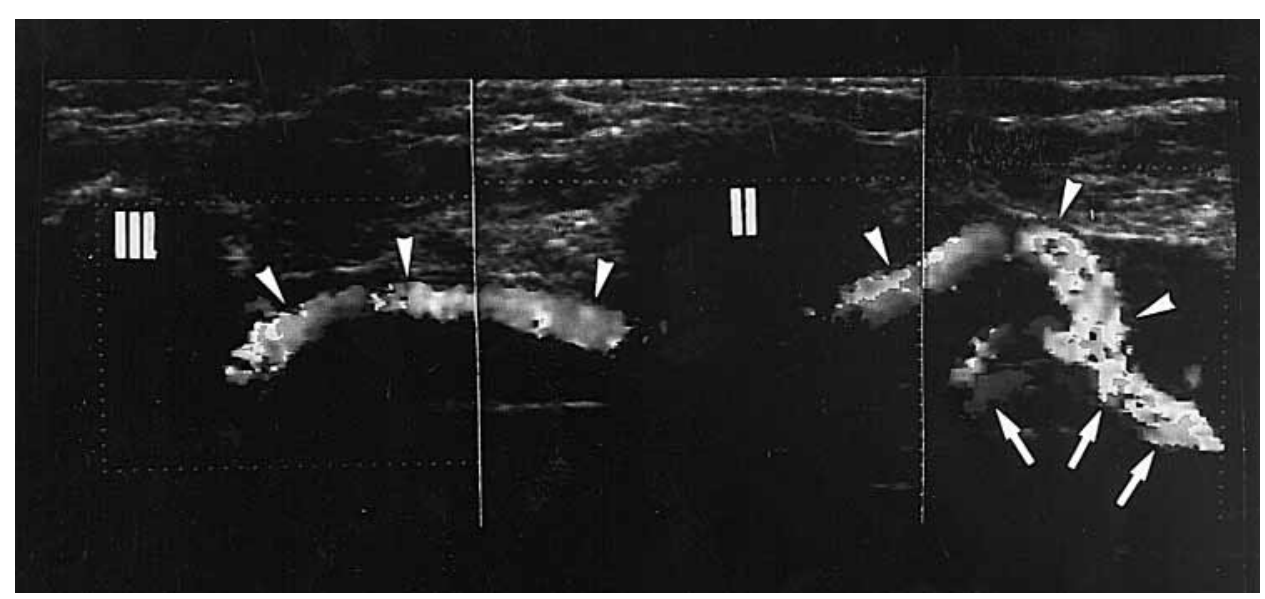

Fig 2. Image of the proximal part of the vein graft (arrowheads) from the right axillary artery (arrows) obtained by transcutaneous echocolor Doppler study performed 2 weeks after pancreatoduodenectomy. II, Second rib; III, third rib.

ligated and divided at its origin, and the GEA pedicle was resected up to a point just proximal to the clip-ligation point.

Comment. The GEA has been used increasingly for coronary artery bypass as the second arterial conduit in situ. ${ }^{1,2}$ Total gastrectomy with preservation of the GEA graft has been reported to be feasible, albeit difficult. ${ }^{3}$ Dietl and colleagues ${ }^{4}$ advocated the retrogastric route of the GEA graft to minimize the risk of graft injury during subsequent laparotomy. However, in particular circumstances, such as the present case, where preservation of the functioning GEA is unachievable, an operation is needed to rescue the graft flow into the coronary artery.

The first report of minimally invasive coronary artery bypass by using a vein graft with an inflow from the axillary artery and an intrapleural route was described by Yaryura and coworkers. ${ }^{5}$ In this technique the intrapleural pathway of the vein graft must be checked carefully to avoid distortion or kinking of the conduit caused by disturbance by the pulmonary tissue. There are 2 particular curves formed along the vein graft requiring special attention: an initial curve at the entry into the chest cavity through the first intercostal space and another curve where the medial margin of the lung tissue contacts the vein graft (Fig 1). Thoracoscopy helps guide the intrapleural pathway of the vein graft, allowing no kinking or twisting.

Because the long-term durability of the present vein graft, which is longer than the standard pathway and has an inflow from the axillary artery, is unknown, strict follow-up will be necessary. Transcutaneous echocolor Doppler evaluation can be performed easily and repeatedly for the proximal part of the vein graft in the infraclavicular area (Fig 2).
In conclusion, the present technique, saphenous vein grafting from the axillary artery to the GEA through an intrapleural route, can be used in particular situations before abdominal surgery to salvage the GEA graft in situ.

Received for publication July 26, 2000; accepted for publication July 31, 2000.

Address for reprints: Toshiya Ohtsuka, MD, Department of Cardiothoracic Surgery, Faculty of Medicine, University of Tokyo, 7-3-1 Hongo, Bunkyo-ku, Tokyo 113-8655, Japan (Email: ohtsuka-tho@h.u-tokyo.ac.jp).

\section{REFERENCES}

1. Suma H, Wanibuchi Y, Terada Y, Fukuda S, Terayama T, Furuta $\mathrm{S}$. The right gastroepiploic artery graft: clinical and angiographic midterm results in 200 patients. J Thorac Cardiovasc Surg 1993;105:615-22.

2. Perrault LP, Rheault MJ, Carrier M. Total gastrectomy in a patient with an in situ right gastroepiploic artery graft. Ann Thorac Surg 1994;57:751-2.

3. Albertini A, Lochegnies A, El Khoury G, et al. Use of the right gastroepiploic artery as a coronary artery bypass graft in 307 patients. Cardiovasc Surg 1998;6:419-23.

4. Dietl CA, Deitrick JE, West JC, Pagana TJ. Laparotomy after using the gastroepiploic artery graft: retrogastric versus anegastric route. Ann Thorac Surg 1995;60:382-5.

5. Yaryura R, Vardhan R, Springer AJ, Cooley DA. A 66-year-old man with severe angina and previous coronary artery bypass. Lancet 1997;349:396. 